Supporting Information

\title{
A Potentiometric Phosphate Ion Sensor Based on Electrochemical Modified Tungsten Electrode
}

Kebin Xu, Ying Li*, Min Li

a School of Metallurgy, Northeastern University, Shenyang 110819, People's Republic of China

b Liaoning Key Laboratory for Metallurgical Sensor Material and Technology, Shenyang 110819 , People's Republic of China

* E-mail: liying@smm.neu.edu.cn 
(a)

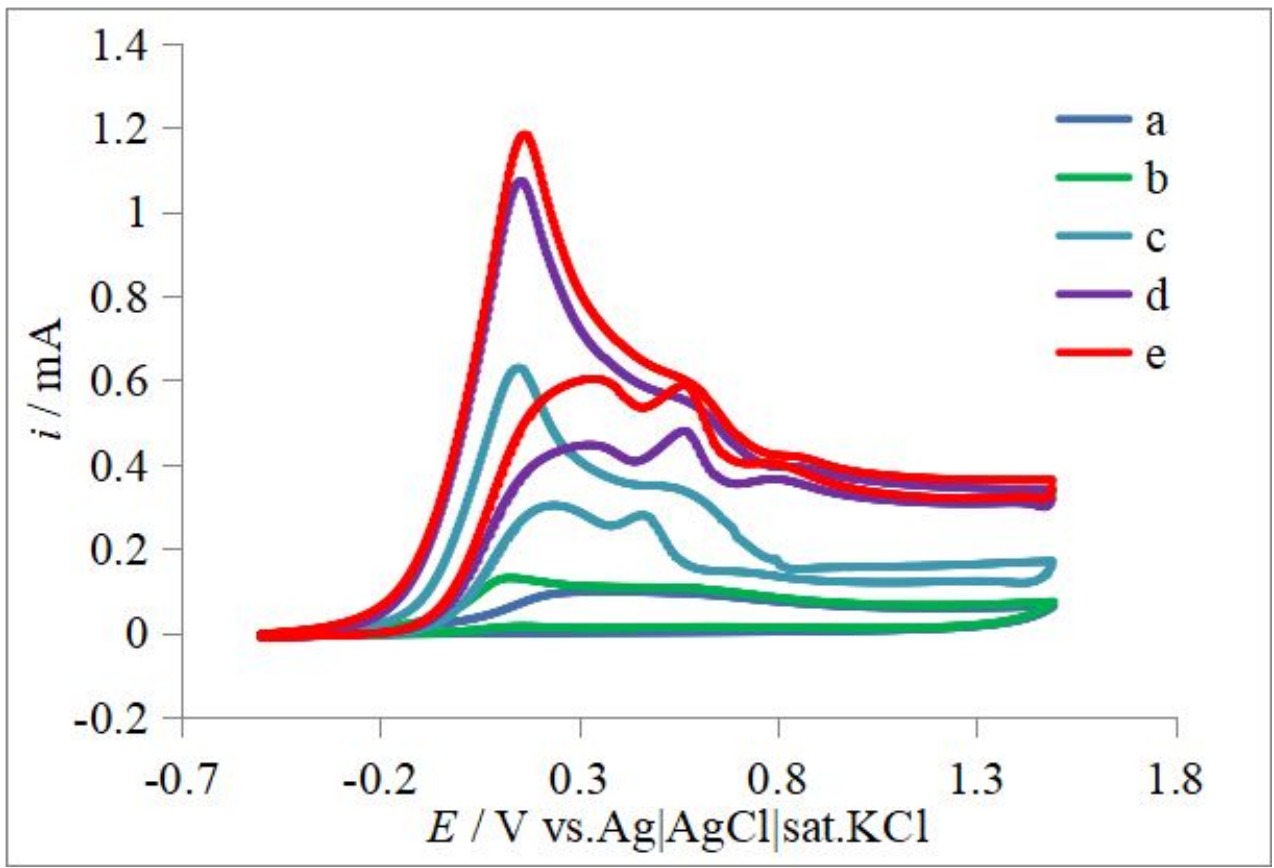

(b)

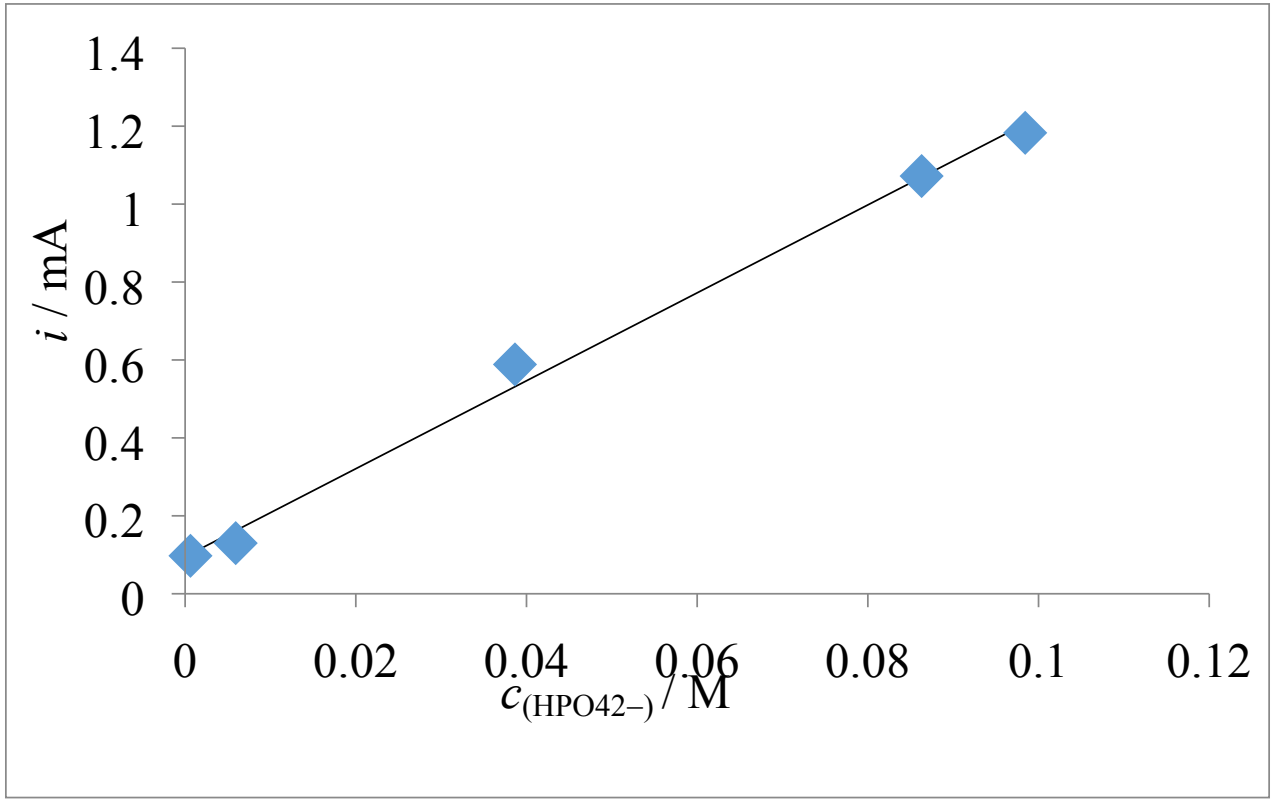

Figure $\mathrm{S} 1$ (a)Cyclic voltammograms in the presence of $0.1 \mathrm{M} \mathrm{Na}_{2} \mathrm{HPO}_{4}$ at various pHs:

(a) $\mathrm{pH} 5.0$, (b) $\mathrm{pH} 6.0$, (c) $\mathrm{pH} 7.0$, (d) $\mathrm{pH} 8.0$, and (e) $\mathrm{pH} 9.0$

(b) $\mathrm{HPO}_{4}{ }^{2-}$ concentration dependence of the cathodic peak current $\left(I_{\mathrm{p}}\right)$ at $0.2 \mathrm{~V}$ 
(a)

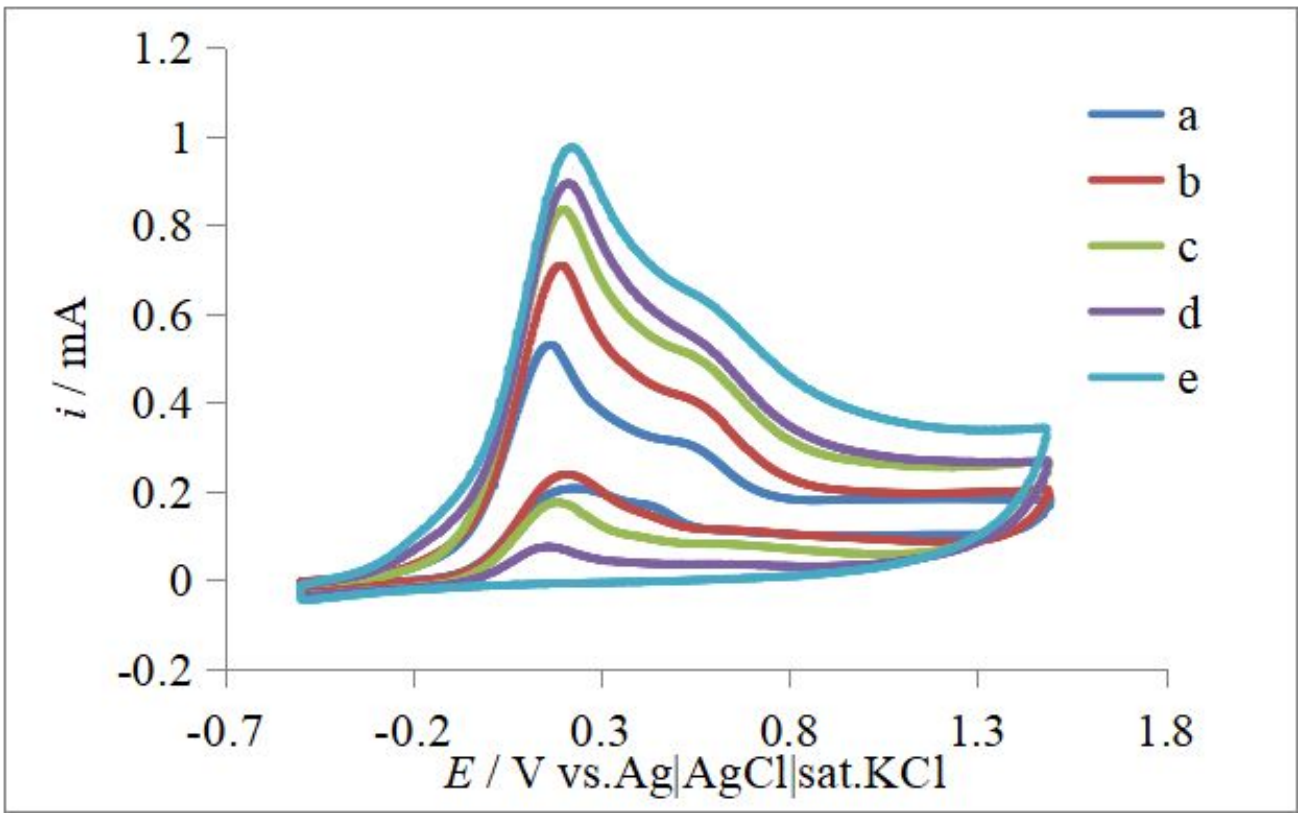

(b)

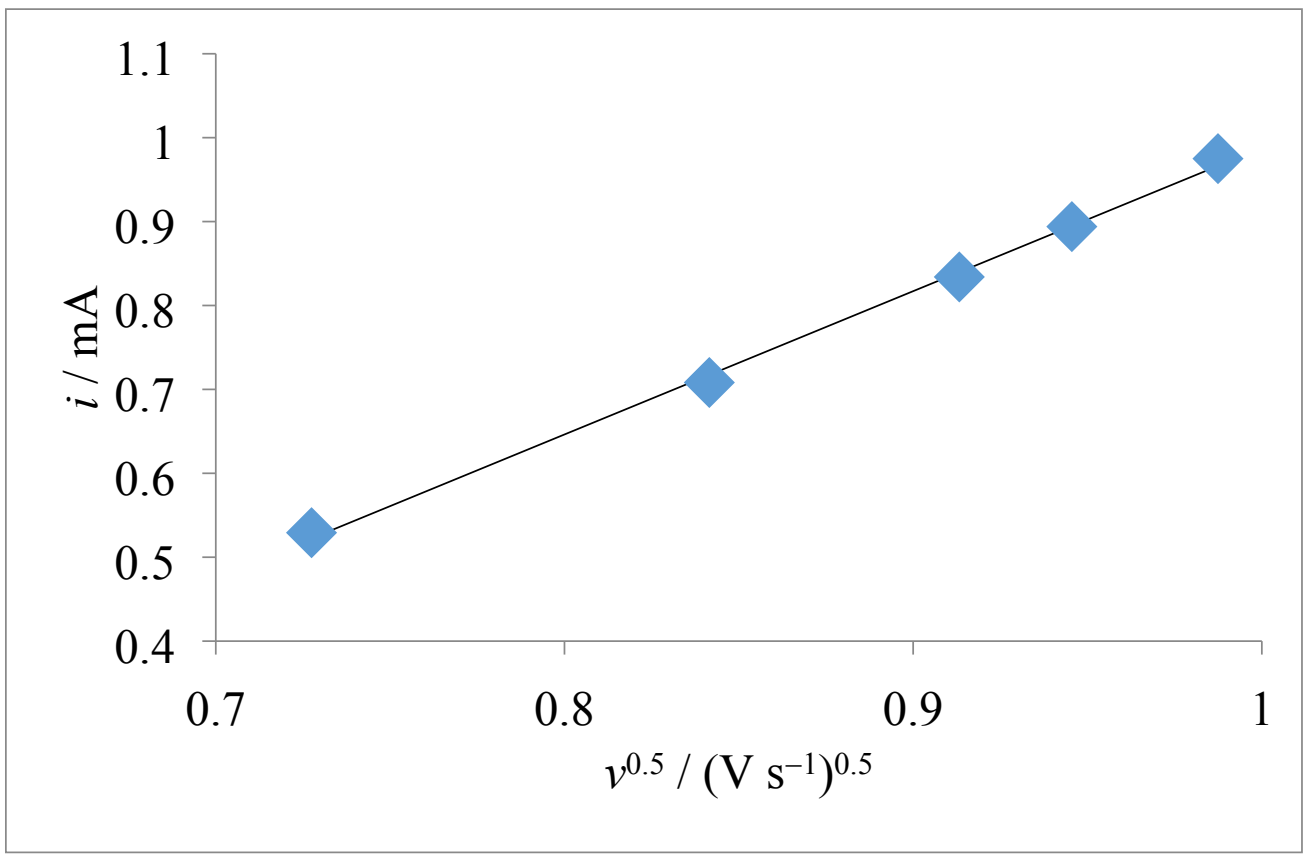

Figure $\mathrm{S} 2$ (a)Cyclic voltammograms in the presence of $0.1 \mathrm{M} \mathrm{Na}_{2} \mathrm{HPO}_{4}$ at $\mathrm{pH} 9.0$ at various scanning rates: (a) $50 \mathrm{mV} \mathrm{s}^{-1}$, (b) $100 \mathrm{mV} \mathrm{s}^{-1}$, (c) $150 \mathrm{mV} \mathrm{s}^{-1}$, (d) $200 \mathrm{mV} \mathrm{s}^{-1}$, and (e) $250 \mathrm{mV} \mathrm{s}^{-1}$.

(b) $\mathrm{HPO}_{4}{ }^{2-}$ concentration dependence of the cathodic peak current $\left(I_{\mathrm{p}}\right)$ at $0.2 \mathrm{~V}$ 


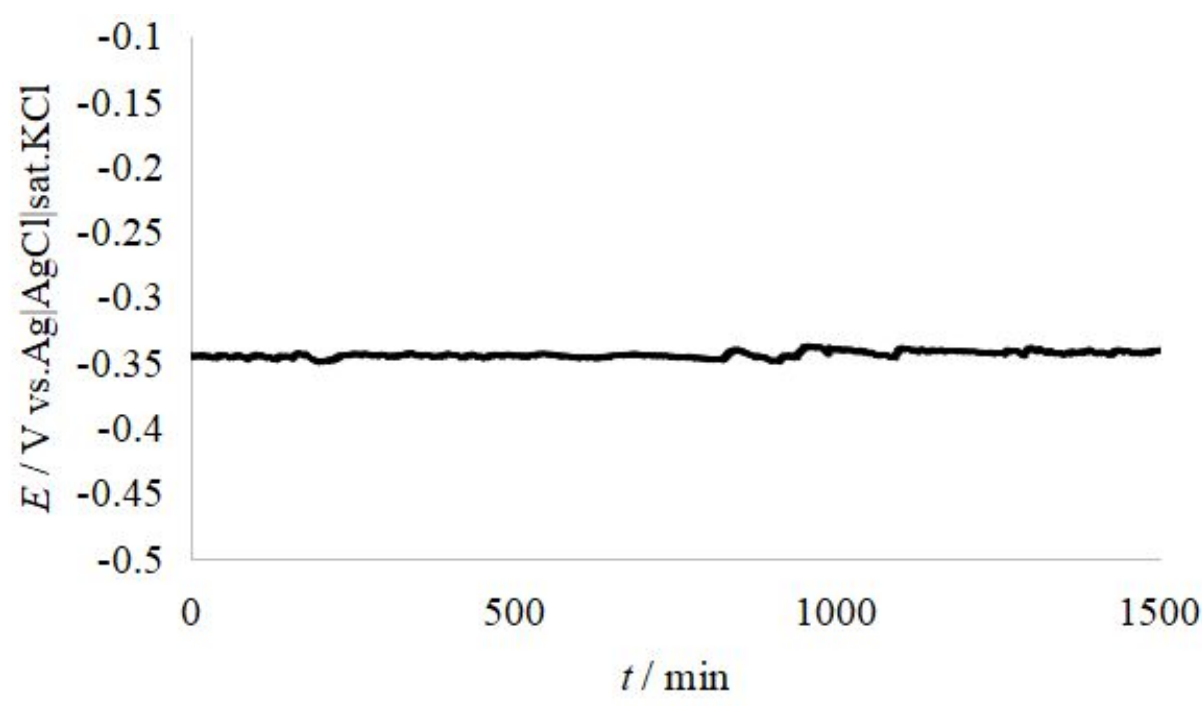

Figure S3. Stability of the modified tungsten electrode for 24 hours 
(a)

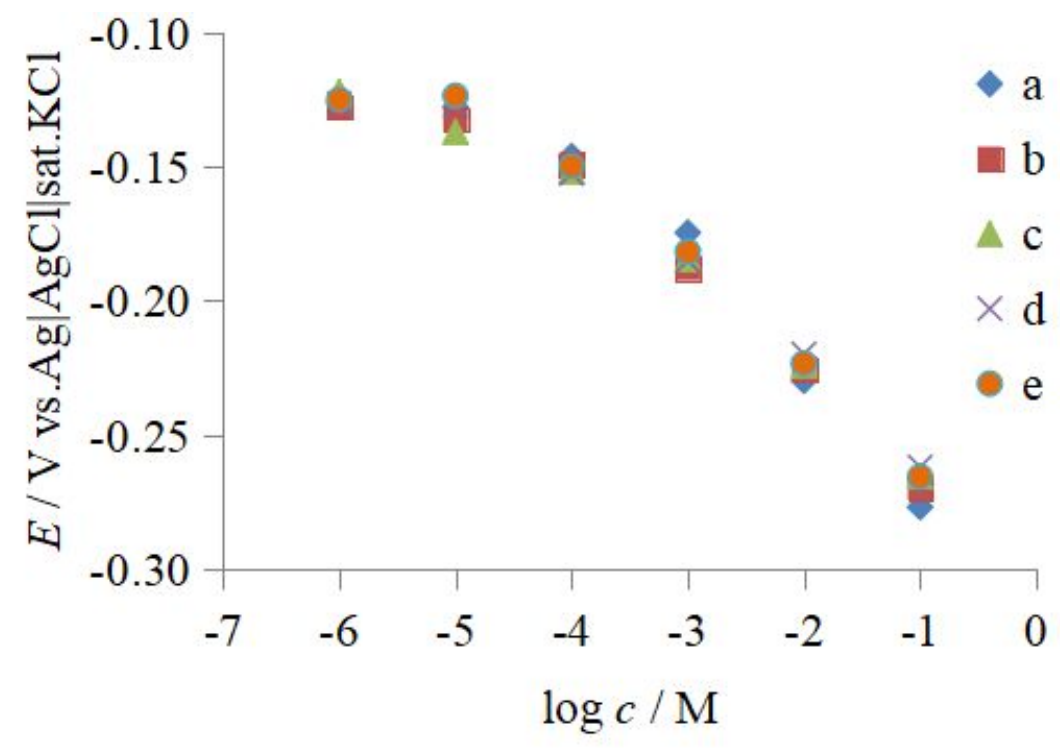

(b)

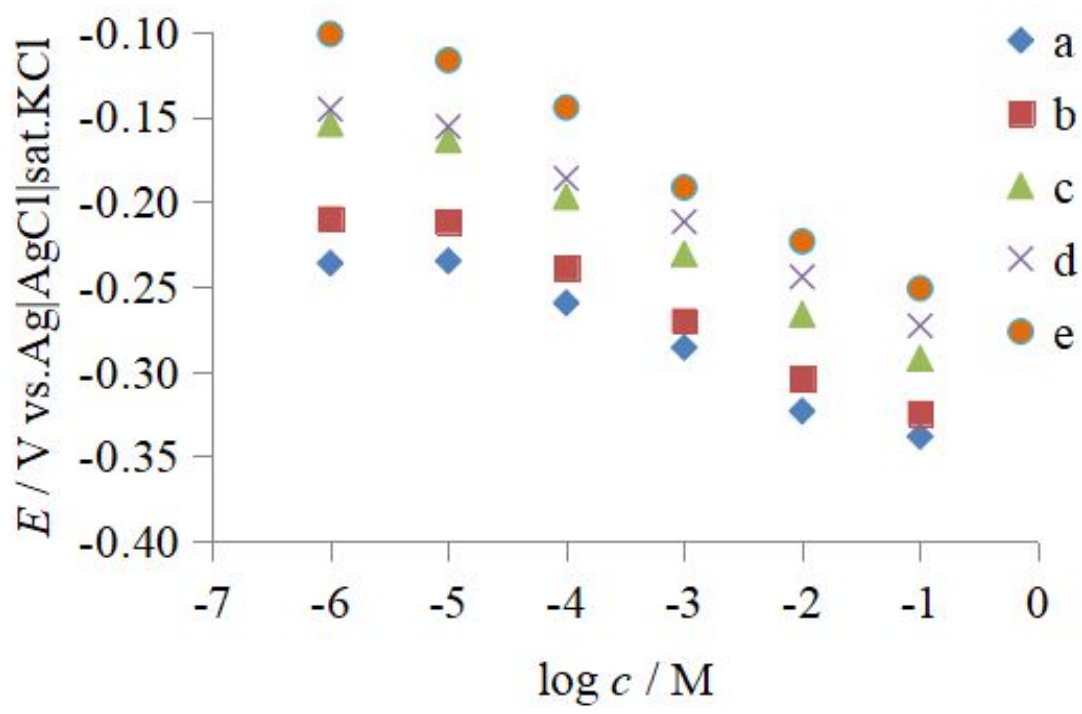

Figure S4. phosphate ion response characteristics of modified tungsten electrode(a) and unmodified tungsten electrode(b) at $\mathrm{pH} 9$. 
(a)

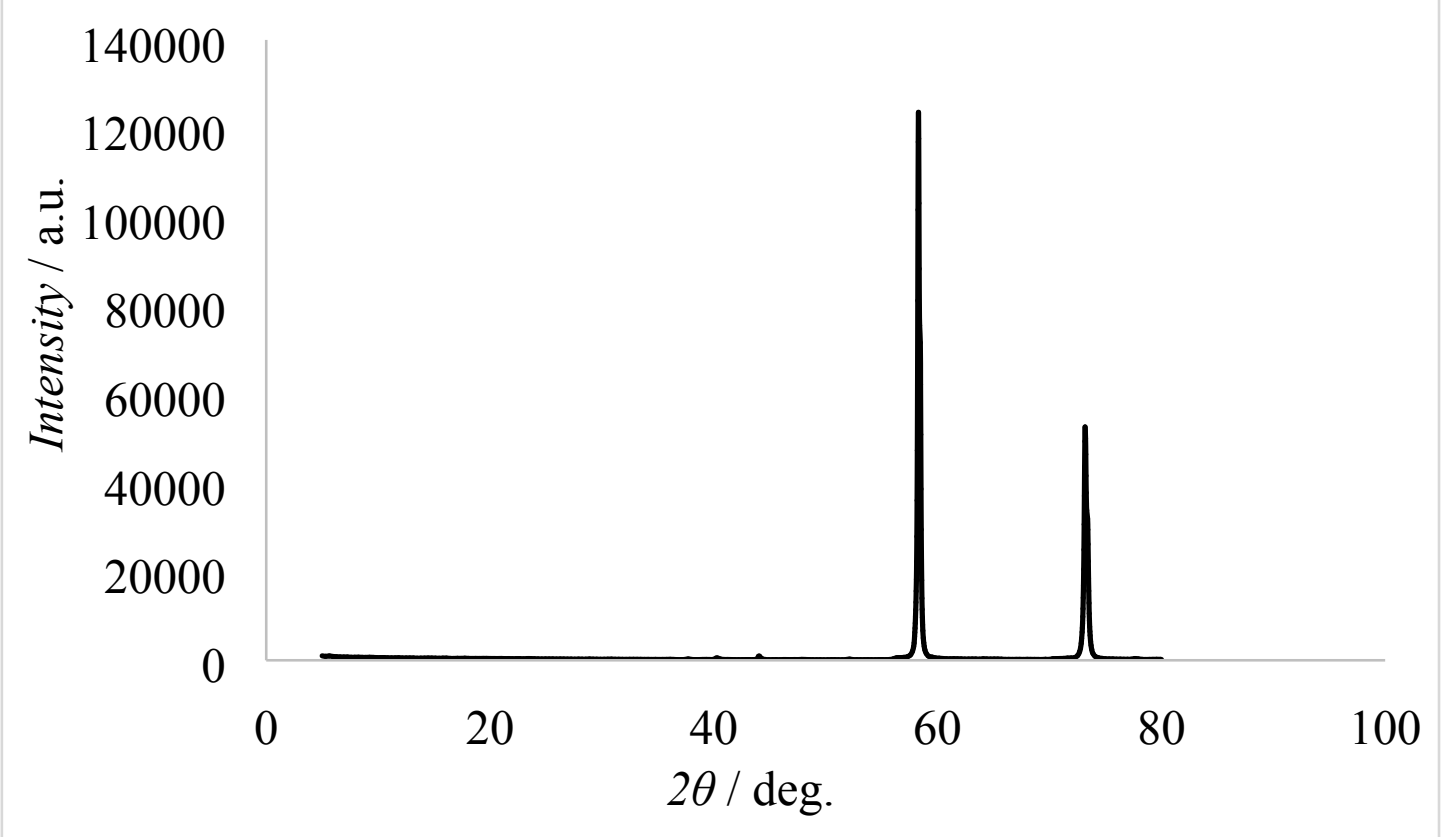

(b)

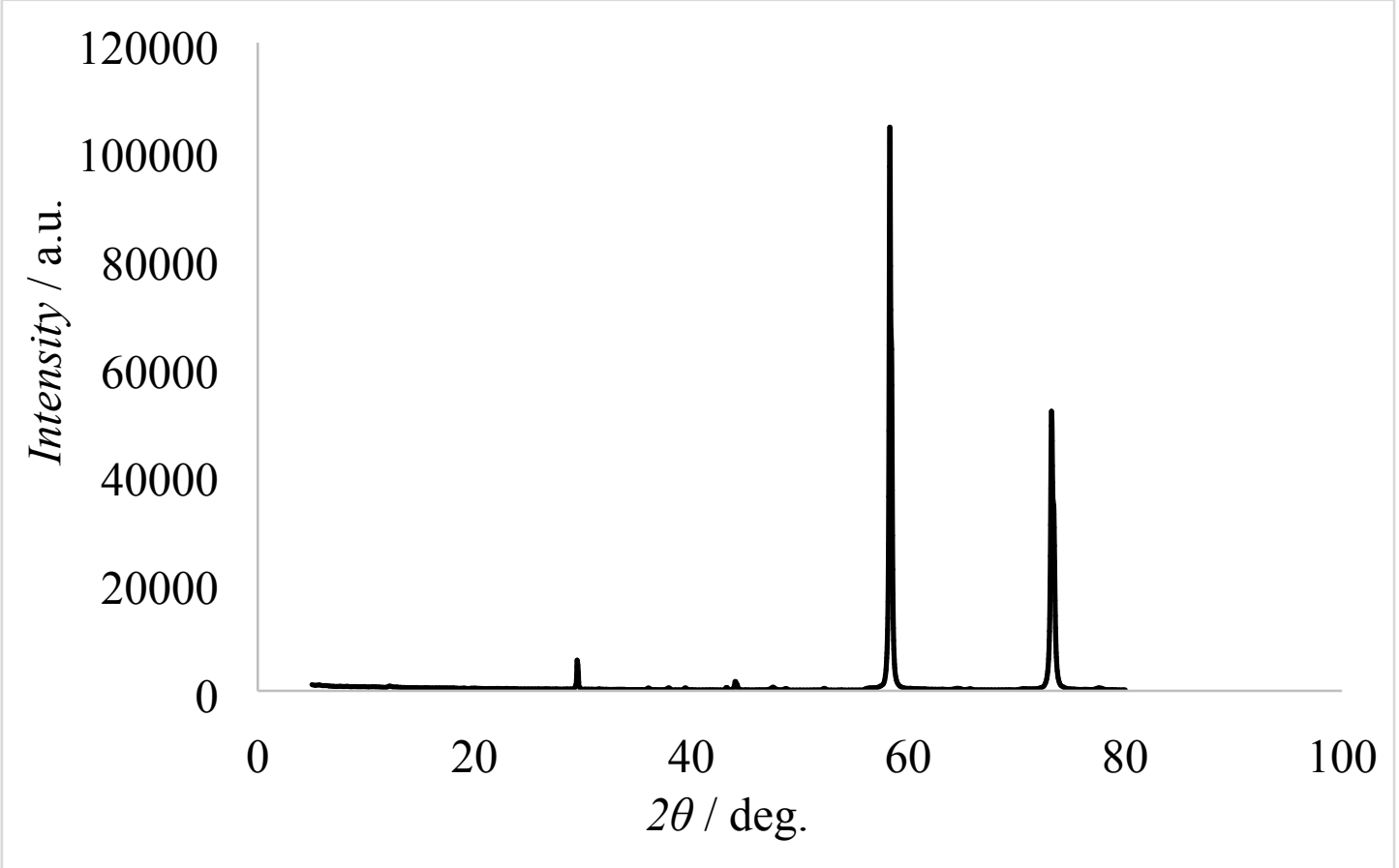

(c) 


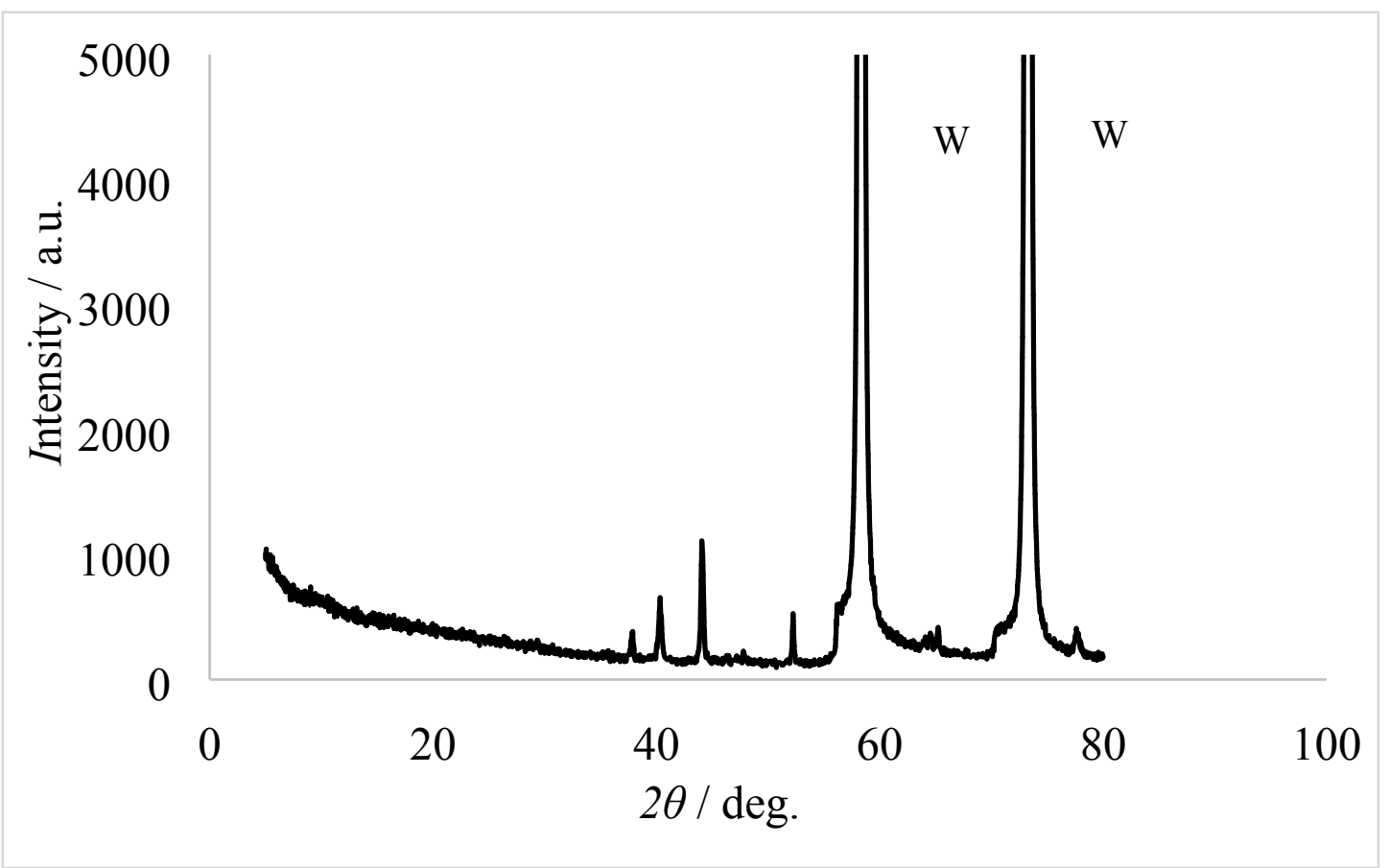

(d)

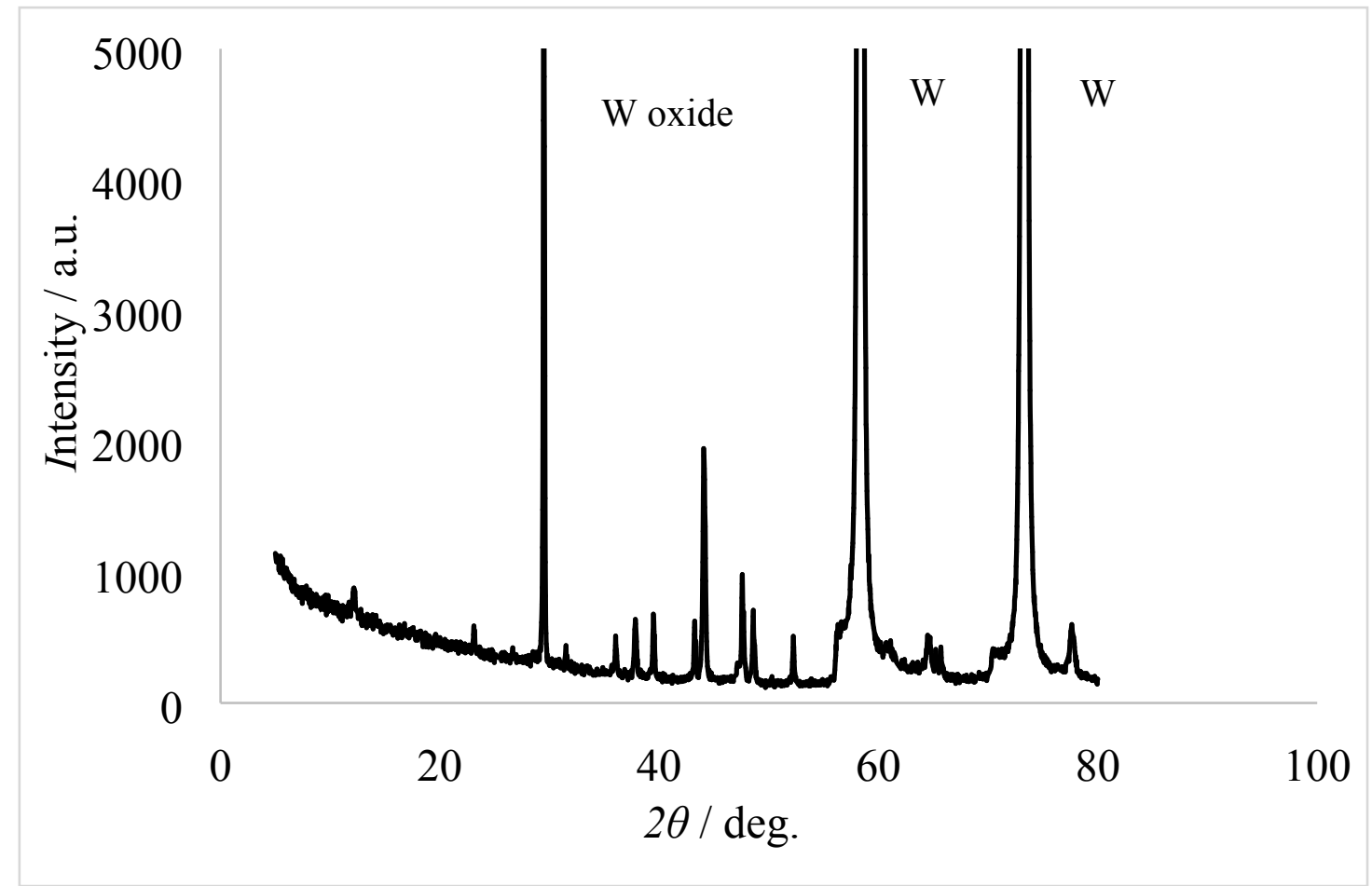

Figure S5. XRD patterns of (a)tungsten pure metal, (b)modified tungsten, (c)local enlarged image of (a) and (d)local enlarged image of (b). 